\title{
Depression and anxiety in medically unwell older adults: prevalence and short-term course
}

\author{
Christina Bryant, ${ }^{1}$ Henry Jackson ${ }^{1}$ and David Ames $^{2}$ \\ ${ }^{1}$ School of Behavioural Science, University of Melbourne, Victoria, Australia \\ ${ }^{2}$ University of Melbourne and National Ageing Research Institute, Royal Melbourne Hospital, Victoria, Australia
}

ABSTRACT

Background: The objective of this study was to examine the prevalence and short-term course of depression and anxiety in a sample of hospitalized, medically unwell older adults, using both a symptom measure and a diagnostic instrument.

\begin{abstract}
Methods: One hundred participants were recruited from in-patients in a geriatric hospital in Melbourne, Australia. Anxiety and depression were assessed shortly after admission, and again two months later, using the Hospital Anxiety and Depression Scale (HADS) and the Geriatric Mental Status Schedule/ AGECAT diagnostic system.

Results: At Time 1, $60 \%$ of the sample exhibited anxiety symptoms at a sub-case level, while $16 \%$ had anxiety symptoms at a syndrome case level, whereas $48 \%$ of the participants had depression at syndrome level. The HADS and AGECAT were concordant with respect to anxiety for $78 \%$ of participants, but agreement was lower for depression; AGECAT identified a further 36 syndrome cases of depression not deemed depressed by the HADS. There was a significant decrease in overall rates of both depression and anxiety symptoms and syndromes from Time 1 to Time 2.
\end{abstract}

Conclusion: This study confirms the findings of previous research with respect to the high prevalence of depression in physically unwell older adults, and extends knowledge about anxiety in this group. Symptoms of anxiety are even more common than symptoms of depression in this group, especially around the time of admission to hospital. Over a relatively short time period, there is a marked reduction in symptoms, but levels of anxiety and depression remain high.

Key words: anxiety, depression, prevalence, older adults, physical illness

\section{Introduction}

While controversy still remains as to the exact prevalence of both anxiety symptoms and anxiety disorders, it is clear that anxiety is common in both community and clinical samples of older people (Lindesay, 1990; Kvaal et al., 2001a; Bryant et al., 2008). The prevalence of anxiety disorder would appear to be around $10 \%$ in community samples (Beekman et al., 1998), and considerably greater in high risk groups, such as carers of people with dementia, with a reported rate of $23.5 \%$ (Mahoney et al., 2005), and $18 \%$ in older adults with chronic pulmonary disease (Yohannes et al.,

Correspondence should be addressed to: Dr Christina Bryant, Senior Lecturer in Clinical Psychology, School of Behavioural Science, Redmond Barry Building, University of Melbourne, Victoria 3010, Australia. Phone: +61 383446371 ; Fax: +6139347 6618. Email: cbryant@unimelb.edu.au. Received 14 Oct 2008; revision requested 12 Jan 2009; revised version received 19 Feb 2009; accepted 19 Feb 2009. First published online 9 June 2009.
2000). Although late-life anxiety has been the focus of far less research than depression, there is good evidence that both anxiety and depression - alone and in combination with physical illness - are linked to poor physical and psychosocial functioning (Lenze, 2001).

Physical health problems are extremely common in older adults, who are heavy users of health services. They have a higher rate of hospital admission than younger people, accounting for $33 \%$ of all hospital admissions in Australia, while comprising only $12 \%$ of the population (Australian Institute of Health and Welfare, 2002). Apart from the cost to the community of this high use of health resources, there are potential costs for the individual. There is evidence that mental and physical health in older people affect each other in reciprocal ways to produce deleterious effects on a range of outcomes. These include increased dependency (Bruce, 2001), decreased satisfaction 
with life (de Beurs et al., 1999) and less favorable outcomes of common health conditions such as stroke (Astrom, 1996; Shimoda and Robinson, 1998), and heart disease (Kroenke et al., 1997; Sullivan et al., 1997). This has given rise to the suggestion that physical health settings are important for mental health intervention in this population (Lichtenberg and MacNeill, 2003). Effective services cannot be planned, however, without accurate knowledge about the prevalence, course, and significance of anxiety (Dorra and Lenze, 2002).

This lack of knowledge is due to the paucity of studies that have sought to establish the prevalence of depression and anxiety in older, medically unwell populations using well-validated instruments, particularly with respect to the measurement of anxiety. Recent studies by Kvaal et al. (2001a) found very high levels of anxiety symptoms in older medical in-patients using the State Trait Anxiety Inventory (STAI) (Spielberger et al., 1983). This instrument does not diagnose anxiety disorder, and the authors subsequently questioned its psychometric properties, in that factor analyses demonstrated two factors in geriatric patients, and only one in healthy controls (Kvaal et al., 2001b). Other studies in physically unwell populations, for example Ames et al. (1994b), used a cross-sectional design. Thus, the objectives of the current study were to examine the prevalence and short-term course of depression and anxiety in a sample of medically unwell older adults, using both a symptom measure and a diagnostic instrument.

\section{Methods}

\section{Participants}

One hundred participants were recruited from consecutive admissions to the Aged Care wards of Melbourne Care and Rehabilitation Service. This is a geriatric and rehabilitation hospital in north-west Melbourne, Australia, serving a catchment area of around 55,000 elderly people. The study received ethics approval from the University of Melbourne Human Research and Ethics Committee and from the Behavioural and Psychiatric Research Committee of Melbourne Health.

To be eligible, participants had to have been admitted to one of the designated wards in the previous five days, be able to give informed consent and have sufficient English to be able to take part in a verbally based assessment process. The initial screening for competence to give consent was by means of the Abbreviated Mental Test Score (Hodkinson, 1972), a 10-item scale in which a cut-off of $7 / 10$ is suggested as indicative of the presence of cognitive impairment. The test does not discriminate between delirium and dementia as the cause of the impairment, so in this instance, a cut-off of $6 / 10$ was used to reduce the likelihood of missing patients in this physically unwell population who had a resolving delirium.

\section{Measures}

Data from a range of domains were collected from participants: demographic information, data pertaining to physical health and functioning, and data pertaining to psychosocial functioning. Symptoms of anxiety and depression were assessed using the Hospital Anxiety and Depression Scale (HADS) (Zigmond and Snaith, 1983), and psychiatric disorder was assessed using the Geriatric Mental Schedule (GMS) (Copeland et al., 1976), a structured instrument developed for the purpose of standardized psychiatric assessment of older people. The information obtained in the GMS interview was analyzed by the AGECAT computer program (Copeland et al., 1986), which yields standardized psychiatric diagnoses with specified confidence levels. The program generates two levels of diagnosis: Stage 1 determines whether symptoms are present from any of eight diagnostic clusters (organic, schizophrenia/paranoia, mania, depression, obsessionality, hypochondriasis, phobia or anxiety). Each of these symptom clusters is given a confidence level from 0 to 5, with levels of 3 and above referred to as "syndrome cases" (Copeland et al., 1986). For example, "an1" indicates the presence of some symptoms of anxiety but at a "subcase" level, while "an3" indicates a syndrome case of anxiety. Confidence levels of 3 and above have been shown to agree well with a psychiatrist's judgment that intervention is justified (Ames et al., 1994a). Theoretically, participants can be syndrome cases or sub-cases on all, any or none of the diagnostic clusters.

Stage 2 of the AGECAT process uses hierarchical rules to produce one main diagnosis. This main diagnosis has a confidence level from 0 to 5, and when this is 3 or greater, this is known as a "diagnostic case"; participants with a main diagnostic label at level 1 or 2 are referred to as "diagnostic sub-cases". Participants who record 0 on all clusters are referred to as "AGECAT well". Depression at case level is divided into neurotic and psychotic subtypes, depending on the symptom profile reported. The hierarchy is such that organic disorders have the highest weighting, and depressive disorders take precedence over anxiety disorders. This is one of the reasons why studies that use the GMS typically report a very low prevalence of anxiety disorders. 
The HADS (Zigmond and Snaith, 1983) is a brief two-dimensional self-report instrument that was originally developed to detect clinically significant depression and anxiety in patients attending a medical outpatient clinic. It was thus important to avoid the confounding effects of physical symptoms, so somatic items are excluded, making it particularly suitable for use with the physically unwell. There are two separate 7-item subscales for depression and anxiety with a score range of $0-21$. A score from 0 to 7 is considered in the normal range, 8-10 indicates mild anxiety or depression, and scores above 11 are regarded as differentiating cases from non-cases. Moderate anxiety or depression is indicated by a score of $11-$ 14 , while severe anxiety or depression is indicated by a score of 15-21 (Snaith and Zigmond, 1994).

\section{Procedure}

Eligible participants gave written consent and were interviewed face-to-face by the first author, who had been trained in the use of the GMS by the third author. The duration of the interview ranged from 40 to 60 minutes. In order to reduce fatigue, the interview was usually carried out in two shorter sessions. The HADS is designed as a self-report measure, but to make the task easier for the participants, the questions were read aloud and their responses recorded by the researcher. This is consistent with other research with older participants reported in the literature (e.g. Houston et al., 2000).

Two months after the initial interview, participants were contacted again. Hospital records were used to establish who had died. In the case of participants who had been discharged from hospital, a letter was sent reminding them about the project. This was followed a few days later by a phone call to arrange a suitable time for the interview. This took place faceto-face in the participant's home or residential facility. Participants who were still in hospital were approached personally by the researcher after consultation with the treating team to check that this was clinically appropriate. All the interviews were carried out by the first author.

\section{Data analysis}

Psychiatric diagnoses were derived from the AGECAT program. Other data were analyzed using SPSS 12. This paper reports descriptive data, including means and $t$-tests relating to psychiatric disorder and symptoms of anxiety and depression derived from the whole data set.

\section{Results}

One hundred participants were recruited and interviewed within one week of admission to hospital (mean 4.5 days, median 5 days). This is referred to as Time 1. Two months later, participants were contacted again for the follow-up interview (Time 2). The mean time to follow-up was 62.8 days and the median 63 days. Between Time 1 and Time 2, nine participants died, five were too ill to be interviewed, four could not be traced and two declined to be interviewed again; this resulted in $80 \%$ of the sample being retained at Time 2 . Of these 80 , two participants were unable to provide a complete dataset because they only wished to be interviewed by telephone. Figure 1 depicts the recruitment and flow of participants.

The average age of the participants was 82.1 years, and females outnumbered males (53\% female, $47 \%$ male). Seventy-two percent had been admitted from an acute general hospital, $18 \%$ from home, $7 \%$ from low-level care and the remainder (3\%) from other sources, such as rehabilitation wards. Two months later, while $36 \%$ had been able to return to their own homes, $26 \%$ either remained in the same hospital or had already been readmitted, indicating the high level of physical morbidity in this population. Seven percent of the participants had been discharged to other rehabilitation hospitals and $4 \%$ had been admitted to an acute hospital. Nearly one in five of the participants was discharged to residential care: $13 \%$ to "low level" care, and $6 \%$ to "high level" care; the latter category is sometimes referred to as "nursing home" care, while the former denotes the ability to carry out some personal selfcare independently.

There was no significant difference between completers and non-completers in terms of gender, age or severity of illness. Although $83.7 \%$ of men were completers, as compared to $77.2 \%$ of women, this was not statistically significant $\left(\chi^{2}=0.46, \mathrm{df}\right.$ $1, \mathrm{~ns})$. The mean age of those lost to follow-up was 83.4 years, compared to 81.8 years for those who were available at Time $2(\mathrm{t}=0.772$, df $98, \mathrm{p}=$ $0.442, n s)$. The number of medications prescribed at the time of admission was taken as a crude measure of physical illness. The mean number of medications being taken by completers was 9.8 , as compared to 11.8 in non-completers, but this failed to reach statistical significance $(\mathrm{t}=.1 .88, \mathrm{df} 95$, $\mathrm{p}=0.064)$.

\section{The prevalence of psychiatric symptoms as measured by the GMS}

Table 1 reports the AGECAT Stage 1 diagnoses at Time 1 and Time 2. As can be seen, the 


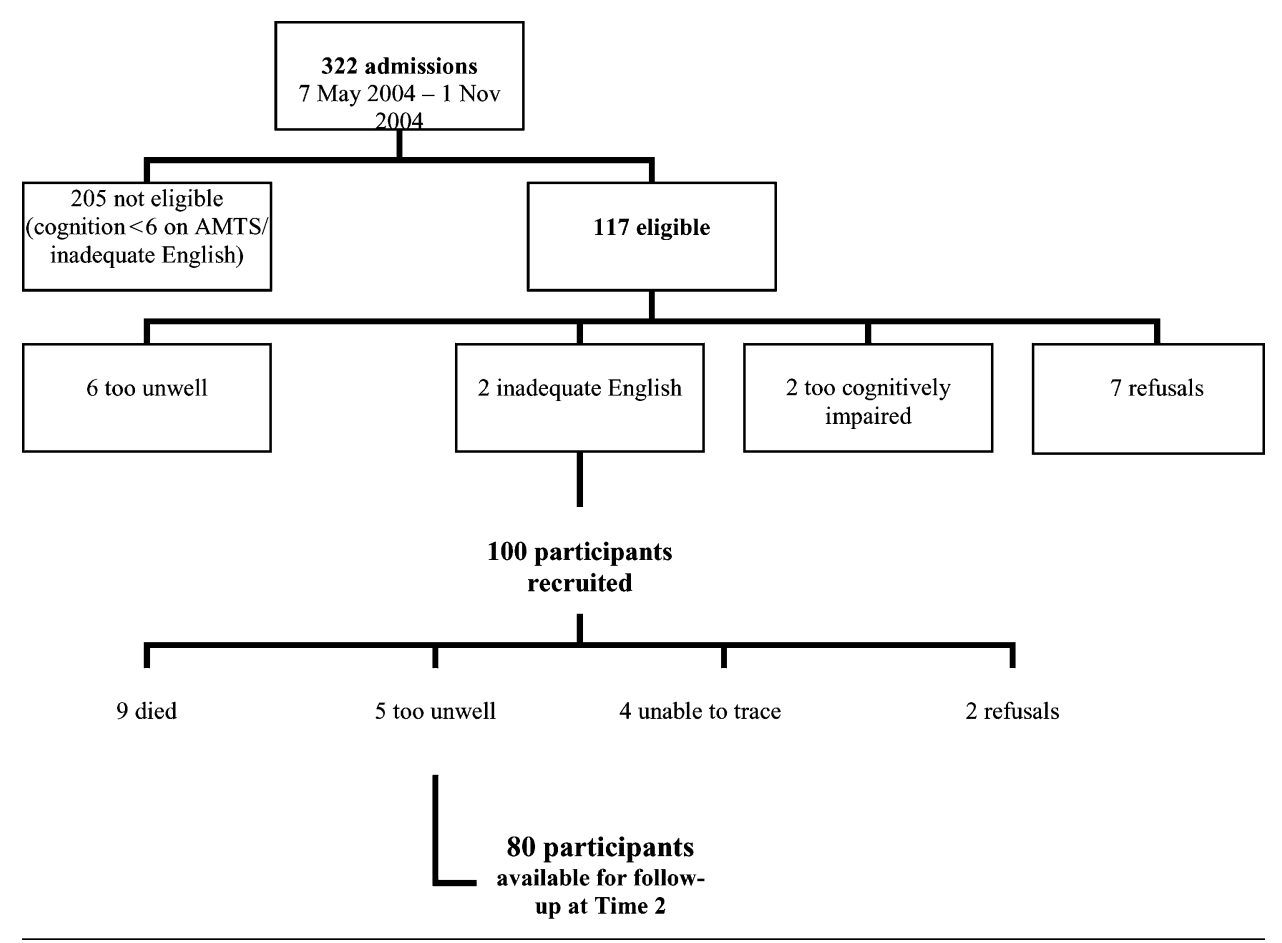

Figure 1. Recruitment of participants.

Table 1. Psychiatric symptoms as measured by the GMS at Time $1(n=100)$ and Time $2(n=78)$

\begin{tabular}{|c|c|c|c|c|}
\hline \multirow[b]{2}{*}{ CONFIDENCE LEVELS } & \multicolumn{2}{|c|}{$1 / 2($ SUB-CASES \% ) } & \multicolumn{2}{|c|}{$\begin{array}{c}3-5 \text { (SYNDROME } \\
\text { CASES\%) }\end{array}$} \\
\hline & TIME 1 & TIME 2 & TIME 1 & TIME 2 \\
\hline Organic impairment & 23 & 13 & 15 & 15 \\
\hline Schizophrenia /Paranoid Psychosis & 10 & 5 & 0 & 1 \\
\hline Mania & 2 & 0 & 0 & 0 \\
\hline Depression & 25 & 12 & 0 & 0 \\
\hline Neurotic & $0^{*}$ & $0^{*}$ & 39 & 29 \\
\hline Psychotic & $0^{*}$ & $0^{*}$ & 9 & 8 \\
\hline Obsessional neurosis & 4 & 0 & 0 & 0 \\
\hline Hypochondriacal neurosis & 1 & 0 & 2 & 0 \\
\hline Phobic neurosis & 13 & 6 & 13 & 5 \\
\hline Anxiety neurosis & 60 & 54 & 16 & 6 \\
\hline
\end{tabular}

${ }^{*}$ For subcase levels of depression, AGECAT does not discriminate between neurotic and psychotic subtypes.

overwhelmingly predominant diagnoses are of anxiety symptoms and depression. At Time 1, 60\% of the sample exhibited sub-case levels of anxiety symptoms, while $16 \%$ had anxiety symptoms at a syndrome case level. Depression was more prevalent than anxiety at a syndromal level, with $48 \%$ of the participants exhibiting either a depressive neurosis or depressive psychosis.

The GMS was administered to all the participants who were available for follow-up at Time 2, and able to take part in the interview (i.e. $78 \%$ of the original sample). As shown in Table 1, there was a decrease in overall rates of psychiatric symptomatology from Time 1 to Time 2 .
In the Stage 2 AGECAT process, which uses hierarchical rules to produce one main diagnosis, depression is a higher order diagnosis than anxiety or phobia, which results in the much smaller numbers of participants who are diagnostic cases of anxiety. In this study, only $5 \%$ of the sample were diagnostic cases of phobic neurosis and 3\% were cases of anxiety neurosis at Time 1 . These, then, are the participants in whom, according to AGECAT, anxiety symptoms predominate over depressive symptoms. As can be seen, depressive neurosis is the most frequent diagnosis of all, with a prevalence of $33 \%$. A further $17 \%$ were sub-cases of depression. Also of note is the small number of 
Table 2. Stage 2 AGECAT psychiatric diagnoses at Time $1(n=100)$ and Time $2(n=78)$

\begin{tabular}{|c|c|c|c|c|}
\hline \multirow[b]{2}{*}{ CONFIDENCE LEVELS } & \multicolumn{2}{|c|}{$\begin{array}{c}1 / 2 \\
(\mathrm{SUB}-\mathrm{CASES} \%)\end{array}$} & \multicolumn{2}{|c|}{$\begin{array}{c}3-5 \text { (SYNDROME } \\
\text { CASES \%) }\end{array}$} \\
\hline & TIME 1 & TIME 2 & TIME 1 & TIME 2 \\
\hline Organic impairment & 4 & 3 & 14 & 14 \\
\hline Schizophrenia /Paranoid Psychosis & 1 & 5 & 0 & 0 \\
\hline Mania & 0 & 0 & 0 & 0 \\
\hline Depression & 17 & 13 & 0 & 0 \\
\hline Neurotic & 0 & 0 & 33 & 22 \\
\hline Psychotic & 0 & 0 & 8 & 6 \\
\hline Obsessional neurosis & 0 & 0 & 0 & 0 \\
\hline Hypochondriacal neurosis & 0 & 0 & 0 & 0 \\
\hline Phobic neurosis & 2 & 1 & 5 & 3 \\
\hline Anxiety neurosis & 8 & 13 & 3 & 0 \\
\hline AGECAT 'well' & & & 5 & 26 \\
\hline
\end{tabular}

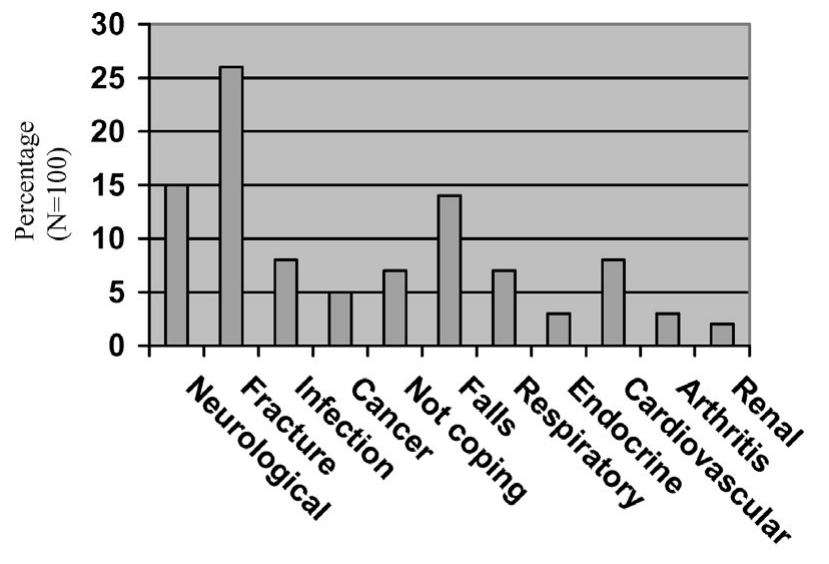

Main diagnosis on admission

Figure 2. Main medical diagnoses of patients on admission.

the sample deemed to be "AGECAT Well", that is, free of any organic or functional psychopathology.

At Time 2, 26\% of the participants were "AGECAT Well", compared to only $5 \%$ at the beginning of the study, and $22 \%$ of the sample were diagnostic cases of depressive neurosis. The percentage of participants with sub-case levels of depression decreased to $11.5 \%$. At Time 2 , there were no diagnostic cases of pure anxiety, but $13 \%$ of the sample were sub-cases of anxiety.

\section{The short-term course of anxiety and depression}

Although overall rates of AGECAT diagnoses were reduced at Time 2, this gives no indication of the course of disorder in individuals. Therefore, diagnostic status at Times 1 and 2 was compared for the 78 participants who were interviewed with the GMS at both times. For the purpose of these analyses, phobic neurosis and anxiety neurosis were considered together, because the number of cases of phobic neurosis was small. As shown in Table 3, only $16 / 78(20 \%)$ of the participants showed stability in AGECAT Stage 2 diagnosis across time; change in status was the norm rather than the exception. There was a marked reduction in clinical anxiety from $16 \%$ of the sample at Time 1 , to $9 \%$ at Time 2 , and a reduction in depression from $41 \%$ to $27 \%$.

\section{Anxiety and depression symptoms as measured by the HADS}

Ninety-eight of the participants were assessed using the HADS at Time 1 and data were available for 78 participants at Time 2. Cronbach's $\alpha$ at Time 1 was 0.78 , and at Time 20.80 , indicating good reliability of the scale. At Time 1, the mean score on the anxiety scale of the HADS was 6.5 (SD +/$4.1)$ and on the depression scale $5.7(\mathrm{SD}+/-4.1)$. At Time 2, the mean score on the anxiety scale of the HADS was $5.6(+/-S D$ 3.7) and on the depression scale $6.1(\mathrm{SD}+/-5.3)$. All of these differences were non-significant.

Using the recommended cut-off score of $11,17 \%$ of the sample were identified by the HADS as having clinically significant anxiety at Time 1 , a similar figure to the $16 \%$ of participants having anxiety symptoms at a syndrome case level according to the GMS. At Time 1, only $13 \%$ of the sample had scores $>11$ on the HADS depression scale, although $17.3 \%$ of the sample scored in the range from 8 to 10 , which is regarded as signifying "mild depression". At Time 2, 9.1\% of the sample had scores $>11$ on the HADS anxiety scale, a marked reduction within a 2 -month time period. At Time $2,24.7 \%$ of the sample scored in the moderate or 
Table 3. Stage 2 diagnosis at Time 1 and Time 2 compared $(n=78)$

\begin{tabular}{|c|c|c|c|c|c|c|c|c|c|c|}
\hline \multirow{2}{*}{$\begin{array}{l}\text { AGECAT DIAGNOSIS } \\
\text { TIME } 1\end{array}$} & \multicolumn{10}{|c|}{ AGECAT DIAGNOSIS TIME 2} \\
\hline & $\mathrm{o} 1 / 2$ & $0>3$ & $\mathrm{~d} 1 / 2$ & $\mathrm{Dn}>3$ & $\mathrm{Dp}>3$ & $\mathrm{~s} 1 / 2 / 3$ & $\operatorname{anx} 1 / 2$ & Anx $>3$ & WELL & TOTAL \\
\hline $\mathrm{o} 1 / 2$ & $\mathbf{0}$ & 1 & 0 & 0 & 0 & 0 & 1 & 0 & 0 & 2 \\
\hline o3 & 1 & 2 & 1 & 3 & 0 & 0 & 1 & 0 & 2 & 10 \\
\hline $\mathrm{d} 1 / 2$ & 0 & 1 & 2 & 3 & 1 & 0 & 3 & 0 & 5 & 15 \\
\hline $\mathrm{Dn}>3$ & 0 & 4 & 3 & 8 & 2 & 0 & 4 & 0 & 5 & 26 \\
\hline $\mathrm{Dp}>3$ & 0 & 1 & 1 & 1 & 1 & 1 & 0 & 0 & 0 & 5 \\
\hline anx $1 / 2$ & 1 & 1 & 0 & 1 & 0 & 1 & 0 & 1 & 3 & 8 \\
\hline Anx $>3$ & 0 & 0 & 1 & 1 & 0 & 0 & 2 & 1 & 3 & 8 \\
\hline well & 0 & 1 & 1 & 0 & 0 & 0 & 0 & 0 & 2 & 4 \\
\hline Total & 2 & 11 & 9 & 17 & 4 & 2 & 11 & 2 & 20 & 78 \\
\hline
\end{tabular}

Numbers in bold represent unchanged diagnostic status.

$\mathrm{o} 1 / 2=$ subclinical organic disorder; $\mathrm{o} 3=$ clinical organic disorder; $\mathrm{d} 1 / 2=$ subclinical depression; $\mathrm{dn}>3=$ neurotic clinical depression; $\mathrm{dp}>3=$ psychotic clinical depression; anx $1 / 2=$ all subclinical anxiety; anx $>3$ = all clinical anxiety; well = AGECAT well.

severe range of the HADS depression scale (i.e. a score $>11$ ).

In order to investigate the concordance between the HADS and the GMS-AGECAT, several new variables were created. Using the recommended cut-offs for the HADS, participants scoring between 0 and 10 were allocated to a category of "no or mild" depression or anxiety; those scoring from 11 to 21 were deemed to have "moderate to severe" depression or anxiety. All the GMSAGECAT Stage 1 anxiety categories (obsessional, hypochondriacal, phobic and anxiety neurosis) were combined into new variables encompassing all anxiety types divided into sub-case and syndrome levels of symptomatology. Stage 1 depressive neurosis and psychosis were combined in one variable for syndrome level depression. Stage 1 diagnoses were used in order to be able to consider all participants who had symptoms of depression or anxiety, prior to the imposition of a hierarchical diagnosis.

At Time 1, the HADS and the AGECAT were concordant with respect to anxiety for $78 \%$ of participants. However, eight of the HADS "anxious" group were non-anxious according to the AGECAT and 14 of the AGECAT's anxious group were not anxious according to the HADS. Agreement between the HADS and AGECAT on depression was reached for $60 \%$ of the cases but the AGECAT identified a further 36 syndrome cases of depression not regarded by the HADS as depressed, while only two people deemed depressed by the HADS cut-off were AGECAT not depressed.

At Time 2, agreement between the AGECAT and the HADS with respect to anxiety was reached for $89.5 \%$ of the sample. Agreement on depression status at Time 2 was $73.7 \%$. The HADS identified three individuals with moderate to severe depression who were not identified as depressed by the AGECAT, but the AGECAT identified a further 17 individuals who were syndrome cases of depression at Time 2, but not depressed according to HADS cut-offs.

\section{Discussion}

In this sample of 100 consecutive admissions to aged care wards, the overwhelmingly predominant GMS diagnoses were of anxiety symptoms and depression. Sixty percent of the sample exhibited sub-case levels of anxiety neurosis, while $16 \%$ were syndrome cases of anxiety neurosis, which could be considered similar to Generalized Anxiety Disorder. Phobic symptoms were also common, with $13 \%$ of the sample deemed to be syndrome cases of phobic anxiety. In contrast to the profile of anxiety symptoms as measured by the GMS-AGECAT, there was a higher prevalence of syndrome cases of depression ( $48 \%$ of the sample) than of subcase symptoms of depression (found in $25 \%$ of the sample).

As a result of the hierarchical AGECAT diagnostic rules used to produce Stage 2 diagnoses, only $5 \%$ of the sample were diagnostic cases of phobic neurosis and 3\% were cases of anxiety neurosis. Depressive neurosis was the most prevalent diagnosis, with $41 \%$ of the sample deemed by the AGECAT to be diagnostic cases of either depressive neurosis $(33 \%)$ or depressive psychosis $(8 \%)$. A further $17 \%$ were deemed to have subclinical depression. This suggests that the majority of anxiety symptoms occurred in the context of depressive disorder. Also of note is that only $5 \%$ of the sample was deemed to be "AGECAT 
well", that is, free of any organic or functional psychopathology.

The GMS diagnosed more cases of syndrome depression than the HADS, an instrument that is widely used but has been questioned by some authors. For example, Beekman et al. (1998) reported that the criterion validity of the HADS anxiety scale was poor compared to that of the Center for Epidemiologic Studies Depression Scale (CES-D; Radloff, 1977). Only one other study has made a direct comparison of the performance of the HADS with that of the GMS-AGECAT in aged care wards (Wattis et al., 1994). The authors found that the HADS depression scale correctly identified only 8 out of 23 GMS cases of depression. In addition, 16 of the 26 people identified by the HADS anxiety scale as anxious were AGECAT cases of depression. The authors concluded that the poor specificity and sensitivity of the HADS made it an ineffective screening instrument.

Between Time 1 and Time 2 there was considerable change in the diagnostic status of the participants. Symptoms of anxiety remained highly prevalent, with $53.8 \%$ of the sample still reporting subclinical levels of anxiety symptoms, but cases of anxiety neurosis were reduced from $16 \%$ to $6 \%$. Syndrome cases of depression were reduced from $48 \%$ of the sample to $37 \%$. Stage 2 diagnoses at Time 2 determined that $26 \%$ of the sample was now "AGECAT well", there were no cases of anxiety neurosis, and the prevalence of depression (either neurotic or psychotic) was reduced from $41 \%$ to $27 \%$ of the sample.

The findings with respect to depression are consistent with the well-established finding of high rates of depression in hospitalized older adults (Koenig et al., 1998; Lenze et al., 2001; Blazer, 2003). Few studies to date have established prevalence rates for anxiety in physically unwell older adults; our finding of high rates of anxiety symptoms as measured with a well-validated diagnostic instrument add to the growing body of data that suggest that anxiety symptoms are extremely common in this age group, especially when physically unwell and in hospital.

Other studies that have used the GMS in an in-patient geriatric population have also found high levels of psychiatric morbidity (Davies et al., 1993; Ames et al., 1994b). Davies et al. sampled consecutive admissions to two geriatric wards in the U.K. and found that the GMS identified $23 \%$ of their sample as being cases of depression and $7 \%$ as being cases of anxiety, somewhat lower rates of anxiety and depression than in the current study. Ames et al. (1994b) conducted their study in the same hospital as the current study, although the composition of the wards has changed somewhat in the intervening years. One important difference, however, is that Ames et al. excluded only a very small number of patients on the grounds that they were mute, too deaf or too ill; cognitive impairment was not an exclusion criterion. Consequently, the most common diagnosis in the Ames et al. (1994b) study was that of organic impairment (44\%).

One of the strengths of the study lies in the follow-up of the sample after two months. The GMS-AGECAT data for the 78 patients who could be interviewed at both time points showed an interesting pattern of change. Most notable was the large increase in the number of "AGECAT well" participants at Time 2, which increased from $5 \%$ to $26 \%$. The prevalence of syndrome level depression had dropped from a total of $48 \%$ to $37 \%$; $6 \%$ of the sample were cases of anxiety neurosis and $5 \%$ were cases of phobic neurosis. Stage 2 of the AGECAT process deemed that there were no diagnostic cases of anxiety neurosis and only 3\% of the sample were diagnostic cases of phobic anxiety. While the sample at Time 2 represents the survivors, there appears to be a marked decrease in psychiatric symptomatology over time.

One reason for the observed changes might be that they reflect the natural course of psychiatric disorder, which may tend to remit and recur. It is likely that a range of factors play a role in this. One possibility, suggested by a number of authors, is that depression and anxiety and physical illness change in tandem with one another (Koenig and George, 1998; Bruce, 2001; Simon et al., 1996). In this view, one would expect symptoms of depression and anxiety to remit as physical illness responds to treatment during the hospital admission.

Another factor that may have contributed to the substantial decreases in psychiatric morbidity in the two months between the two data collection points in the current study is the timing of the initial interviews. These took place within five days of admission to hospital and it could be argued that this would be a time of particularly elevated levels of anxiety, worry and mood disturbance in reaction to the recent life event of hospitalization. One would therefore expect a decrease in symptoms as adaptation to new circumstances takes place. This would be consistent with a view that the symptoms observed at that time represent distress, rather than depression or frank psychiatric disturbance, as suggested by Lloyd and Cawley (1983) in their study of depression after in-patient treatment of myocardial infarct.

A further aspect of the data that requires comment is the pattern of change seen between the two time-points. Comparison of the diagnostic status of the participants interviewed at both times showed that only $20 \%$ of the sample were in the 
same diagnostic category at Time 1 and Time 2 . Although some of the movement - for example, from the neurotic depression diagnosis - was to being "AGECAT well", there was also some movement between the depression and the anxiety categories. This is consistent with a view that anxiety and depression are part of what has been described as a general neurotic syndrome (Tyrer, 1990). One of the arguments in favor of the concept of neurosis is the instability of diagnostic anxiety disorder categories over time (Lindesay, 1994), as seen in the current study.

The study has a number of important strengths, including the use of a diagnostic instrument validated for use with older adults, the use of a longitudinal, rather than cross-sectional design, and its focus on anxiety, which has received far less research attention than depression. Moreover, this study sought to address the under-representation of participants who are physically unwell or frail in research on older age groups. The findings do, however, need to be interpreted in the light of the study's limitations. The primary shortcoming of the study is its relatively small sample size, compounded by attrition even over the relatively short time scale of the data collection, a problem that is ubiquitous and unavoidable in research with older adults (Bond et al., 1998). Moreover, our exclusion criteria resulted in a sample that was not truly representative of all the patients in geriatric wards. Rather, it represents a sample of patients who may be expected to fare better as they were less cognitively impaired and spoke good English, two factors that may contribute to better participation in rehabilitation programs. A further issue is that we do not have data on the length of stay of the patients during their acute hospital admission, which may have a bearing on the outcome of the hospital episode under consideration in this study.

A further caveat with respect to the AGECAT should be noted, as it has been suggested that the AGECAT tends to over-diagnose depression at the expense of other diagnoses, such as adjustment disorder and uncomplicated bereavement (Ames et al., 1994a). These authors compared the AGECAT with DSM-IIIR diagnoses in an inpatient population and found that 15 of the 49 individuals identified by the AGECAT as depressed were non-cases using DSM-IIIR criteria. It may be, therefore, that the levels of depression in this sample were somewhat inflated by the AGECAT's diagnostic algorithm, which appears to give considerable weight to depressive symptoms. The present study did not have the resources to include psychiatrist-conducted interviews, and the question remains as to whether a psychiatrist using DSM-IV criteria (American Psychiatric
Association, 1994) would have regarded some of the current cases of depression as cases of adjustment disorder.

\section{Conclusion}

This study confirms the findings of previous research with respect to the high prevalence of depression in physically unwell older adults, and extends knowledge about anxiety in physically unwell older adults. Symptoms of anxiety are even more common than symptoms of depression in this group, especially around the time of admission to hospital. Over a relatively short time period, there is a marked reduction in symptoms, but levels of anxiety and depression remain high, which may have implications for recovery and treatment planning.

Although the ascertainment of psychiatric symptoms and diagnoses was carried out using a well-validated and widely used diagnostic interview, the results of this study highlight some of the complexities in ascertaining the prevalence of anxiety and depression in clinical samples. The possible tendency of the GMS to over-diagnose depression, the likelihood that in the early days of hospital admission measures of anxiety and depression may be inflated, together with the problem of attrition in a frail sample, all make the goal of establishing accurate epidemiological data in this population challenging. Further research should aim to corroborate data against psychiatric interview and use multiple time points to examine the course of depression and anxiety.

\section{Conflict of interest declaration}

David Ames is the editor-in-chief of International Psychogeriatrics; this paper was therefore reviewed through the office of the deputy editor, Professor O'Brien.

\section{Description of authors' roles}

C. Bryant designed and collected the data for the study as her $\mathrm{PhD}$ research project under the supervision of $\mathrm{H}$. Jackson and D. Ames. C. Bryant analysed the data and wrote the paper with assistance from $\mathrm{H}$. Jackson and D. Ames.

\section{Acknowledgment}

C. Bryant received scholarship support through NHMRC grant number 310655. 


\section{References}

American Psychiatric Association (1994). Diagnostic and Statistical Manual of Mental Disorders, 4th edn. Washington, DC: American Psychiatric Association.

Ames, D., Flynn, E., Tuckwell, V. and Harrigan, S. (1994a). Diagnosis of psychiatric disorder in elderly general and geriatric hospital patients: AGECAT and DSM-III compared. International fournal of Geriatric Psychiatry, 9, 627-633.

Ames, D., Flynn, E. and Harrigan, S. (1994b). Prevalence of psychiatric disorders among in-patients in an acute geriatric hospital. Australian fournal on Ageing, 13, $8-11$.

Astrom, M. (1996). Generalised Anxiety Disorder in stroke patients. Stroke, 27, 270-275.

Australian Institute of Health and Welfare (2002). Older Australia at a Glance. Canberra: Australian Institute of Health and Welfare and Department of Ageing.

Beekman, A. et al. (1998). Anxiety disorders in later life: a report from the Longitudinal Aging Study, Amsterdam. International fournal of Geriatric Psychiatry, 13, 717726.

Blazer, D. (2003). Depression in late life: review and commentary. Fournal of Gerontology, Medical Sciences, 58, 249-265.

Bond, R., Gregson, B., Rousseau, N., Lecoutier, J. and Rodgers, H. (1998). Outcomes following acute hospital care for stroke or hip fracture: how useful is an assessment for anxiety? International fournal of Geriatric Psychiatry, 13, 601-610.

Bruce, M. (2001). Depression and disability in late life. American fournal of Geriatric Psychiatry, 9, 102-112.

Bruce, M., Seeman, T., Merrill, S. and Blazer, D. (1994). The impact of depressive symptomatology on physical disability: MacArthur Studies of Successful Aging. American fournal of Public Health, 84, 1796-1799.

Bryant, C., Jackson, H. and Ames, D. (2008). The prevalence of anxiety in older adults: methodological issues and a review of the literature. Fournal of Affective Disorders, 109, 233-250.

Copeland, J., Kelleher, M., Kellett, J., Gourlay, A., Gurland, B. and Fleiss, J. (1976). A semi-structured instrument for the assessment and diagnosis of mental state in the elderly: the Geriatric Mental State Schedule. Psychological Medicine, 6, 439-449.

Copeland, J., Dewey, M., and Griffith-Jones, H. (1986). A computerised psychiatric diagnostic system and nomenclature for elderly subjects. Psychological Medicine, $16,88-99$.

Davies, K., Burn, W., McKenzie, F. and Brothwell, J. (1993). Evaluation of the Hospital Anxiety and Depression Scale as a screening instrument in geriatric medical patients. International fournal of Geriatric Psychiatry, 8, 165-169.

de Beurs, E., Beekman, A., van Balkom, A., Deeg, D., van Dyck, R. and van Tilburg, W. (1999). Anxiety in older persons: its effect on disability, well-being and use of health services. Psychological Medicine, 29, 303-316.

Dorra, H. and Lenze, E. (2002). Clinically relevant factors in elderly hip fracture patients. International fournal of Psychiatry and Medicine, 32, 249-259.
Hodkinson, M. (1972). Evaluation of a mental test score for the assessment of mental impairment in the elderly. Age and Ageing, 1, 233-238.

Houston, D., McKee, K. and Wilson, J. (2000). Attributional style, efficacy and the enhancement of well-being among housebound older people. Basic and Applied Social Psychology, 22, 309-317.

Koenig, H. and George, L. (1998). Depression and physical disabilitry outcomes in depressed medically ill hospitalised older adults. Gerontologist, 28, 308-310.

Koenig, H., Gittleman, D., Branski, S., Brown, S. and Stone, P. (1998). Depressive symptoms in elderly medical-surgical patients hospitalized in community settings. American fournal of Geriatric Psychiatry, 6, 14-23.

Kroenke, K., Jackson, J. and Chamberlin, J. (1997). Depressive and anxiety disorders in patients presenting with physical complaints: clinical predictors and outcome. American fournal of Medicine, 103, 339-347.

Kvaal, K., Macijauskiene, J., Engedal, K. and Laake, E. (2001a). High prevalence of anxiety symptoms in hospitalised geriatric patients. International fournal of Geriatric Psychiatry, 16, 690-693.

Kvaal, K., Laake, K. and Engedal, K. (2001b). Psychometric properties of the state part of the Spielberger State-Trait Anxiety Inventory (STAI) in geriatric patients. International fournal of Geriatric Psychiatry, 16, 980-986.

Lenze, E. et al. (2001). The association of late-life depression and anxiety with physical disability: a review of the literature and prospectus for future research. American Fournal of Geriatric Psychiatry, 9, 113-135.

Lichtenberg, P. and MacNeill, S. (2003). Streamlining assessments and treatments for geriatric mental health in medical rehabilitation. Rehabilitation Psychology, 48, 56-60.

Lindesay, J. (1990). The Guy's /Age Concern survey: physical health and psychiatric disorder in an urban elderly sample. International fournal of Geriatric Psychiatry, 5, 171-178.

Lindesay, J. (1994). Neurotic disorders. In D. Ames and E. Chiu (eds.), Functional Psychotic Disorders of the Elderly. Cambridge: Cambridge University Press.

Lloyd, G. and Cawley, R. (1983). Distress or illness? A study of psychological symptoms after myocardial infarction. British fournal of Psychiatry, 142, 120-125.

Mahoney, R., Regan, C., Katona, C. and Livingston, G. (2005). Anxiety and depression in family caregivers of people with Alzheimer's disease. American fournal of Geriatric Psychiatry, 13, 795-801.

Radloff, L. (1977). The CES-D Scale: a self-report depression scale for research in the general population. Applied Psychological Measurement, 1, 385-390.

Shimoda, K. and Robinson, R. (1998). Effect of anxiety disorder on recovery from stroke. Fournal of Neuropsychiatry and Clinical Neuroscience, 10, 34-40.

Simon, G., Gater, R., Kisely, S. and Piccinelli, M. (1996). Somatic symptoms of distress: an international primary care study. Psychosomatic Medicine, 58, 481-488.

Snaith, R. and Zigmond, A. (1994). The Hospital Anxiety and Depression Scale Manual. Windsor: NFER.

Spielberger, C., Gorusch, R., Lushene, P., Vagg, P. and Jacobs, A. (1983). Manual for the State-Trait Anxiety Inventory (Form Y). Palo Alto, CA: Consulting Psychologists' Press Inc. 
Sullivan, M., LaCroix, A., Baum, C. and Grothaus, L. (1997). Functional status in coronary artery disease: a one-year prospective study of the role of anxiety and depression. American fournal of Medicine, 103, 348-356.

Tyrer, P. (1990). The division of neurosis: a failed classification. Fournal of the Royal Society of Medicine, 83, 614-616.

Wattis, J., Davies, K., Burn, W. and McKenzie, F. (1994). Correlation between Hospital Anxiety and Depression (HAD) Scale and other measures of anxiety and depression in geriatric inpatients. International fournal of Geriatric Psychiatry, 9, 61-63.

Yohannes, A., Baldwin, R. and Connolly, M. (2000). Depression and anxiety in elderly outpatients with chronic obstructive pulmonary disease: prevalence, and validation of the BASDEC screening questionnaire. International fournal of Geriatric Psychiatry, 15, 1090-1096.

Zigmond, A. and Snaith, R. (1983). The Hospital Anxiety and Depression Scale. Acta Psychiatrica Scandinavica, 67, 361-370. 


\section{University Library}

\section{- M M I N E R VA A gateway to Melbourne's research publications}

Minerva Access is the Institutional Repository of The University of Melbourne

Author/s:

Bryant, C;Jackson, H;Ames, D

Title:

Depression and anxiety in medically unwell older adults: prevalence and short-term course

Date:

2009-08-01

Citation:

Bryant, C., Jackson, H. \& Ames, D. (2009). Depression and anxiety in medically unwell older adults: prevalence and short-term course. INTERNATIONAL PSYCHOGERIATRICS, 21 (4), pp.754-763. https://doi.org/10.1017/S1041610209009399.

Publication Status:

Published

Persistent Link:

http://hdl.handle.net/11343/32978 